\title{
Diet quality and change in anthropometric measures: 15-year longitudinal study in Australian adults
}

\author{
Simin Arabshahi ${ }^{1,2}$, Jolieke C. van der Pols ${ }^{1}$, Gail M. Williams ${ }^{2}$, Geoffrey C. Marks ${ }^{2}$ \\ and Petra H. Lahmann ${ }^{1 *}$ \\ ${ }^{1}$ Cancer and Population Studies, Queensland Institute of Medical Research, 300 Herston Road, Herston, Brisbane, \\ QLD 4006, Australia \\ ${ }^{2}$ School of Population Health, The University of Queensland, Herston, Brisbane, QLD 4006, Australia
}

(Submitted 9 January 2011 - Final revision received 20 May 2011 - Accepted 8 July 2011 - First published online 26 August 2011)

\begin{abstract}
Evidence from longitudinal studies on the association between diet quality and change in anthropometric measures is scarce. We therefore investigated the relationship between a recently developed food-based dietary index and change in measured BMI and waist circumference (WC) in Australian adults (1992-2007). We used data from the Australian population-based Nambour Skin Cancer Study comprising 1231 adults aged 25-75 years at baseline (1992). We applied generalised estimating equations (GEE) to examine the association between diet quality and change in anthropometric measures. Dietary intake was assessed by an FFQ in 1992, 1996 and 2007 . Diet quality was estimated using the dietary guideline index (DGI), developed to reflect the dietary guidelines for Australian adults; a higher score indicating increased compliance. Multivariable models, stratified by sex, were adjusted for sociodemographic and lifestyle characteristics. We show that men with higher diet quality had a lower gain in BMI as compared to those with low diet quality during the 15-year follow-up. In a multivariable adjusted model, as compared to men in quartile 1 (reference), those in the highest quartile had the lowest gain in BMI (mean (95\% CI): $0.05(0.00,0.09) v \cdot 0 \cdot 11(0.06,0 \cdot 16) \mathrm{kg} / \mathrm{m}^{2}$ per year, $\left.P=0.01\right)$. Diet quality was inversely, but non-significantly associated with change in WC. In women, DGI score was unrelated to change in any body measure. Energy underreporting did not explain the lack of association. We conclude that adherence to a high-quality diet according to Australian dietary guidelines leads to lower gain in BMI and WC in middle-aged men, but not in women.
\end{abstract}

Key words: BMI change: Waist circumference: Dietary guideline index: Prospective studies: Australia

Obesity is a growing health problem in Australian adults ${ }^{(1)}$. According to the most recent national data in 2007-08, 25\% of individuals aged $\geq 18$ years are obese and $37 \%$ are overweight $^{(2)}$. Overweight and obesity are associated with a significant burden of comorbidity from chronic disease ${ }^{(3)}$. Diet is a major modifiable determinant of obesity. Research concerning the effect of diet in obesity development and associated chronic disease has tended to focus on the role of individual nutrients and foods; however, development of methods to assess the overall quality of diet has recently received significant attention ${ }^{(4,5)}$. Dietary indices are based on optimal dietary patterns and provide summary measures of overall diet quality using scoring systems determined by a priori dietary recommendations.

Few studies have investigated the longitudinal association between overall quality of diet and obesity and such information is lacking in Australia. We applied a recently developed food-based dietary index, the dietary guideline index (DGI score $)^{(6)}$, to assess diet quality. The DGI score is based on the Dietary Guidelines for Australian Adults ${ }^{(7)}$ and the Australia Guide to Healthy Eating ${ }^{(8)}$ and reflects current guidelines for optimal eating patterns. The aim of the present study was to investigate the associations between diet quality and change in BMI and waist circumference (WC) in participants of the Nambour Skin Cancer Study over 15 years of follow-up.

\section{Study design and methods}

\section{Study population}

The Nambour Skin Cancer Study involved a random, community-based sample of Australian men and women during their transition from young adulthood to older age. The design, study population, baseline data collection and follow-up methods have previously been described in detail $^{(9,10)}$.

Abbreviations: DGI, dietary guideline index; EI, energy intakes; GEE, generalised estimating equations; WC, waist circumference. 
In brief, participants were 1621 residents of the Nambour township, Queensland, who were originally randomly selected from the electoral roll (voting is compulsory in Australia) and had participated in the Nambour Skin Cancer Prevention Trial (1992-6) and were followed up until 2007. Almost all study participants (99.7\%) were of Caucasian descent.

BMI was measured at a study clinic by trained staff in 1992, 1996 and 2007; and WC was measured in 1992 and 2007. Participants with available dietary data were included in the present analyses if they had BMI data available for at least one of the three time points and WC data available for at least one of the two time points. Of the total 1621 participants (56\% women) who enrolled in the Nambour Skin Cancer Prevention Trial in 1992, the analytical cohort for this study consisted of 1231 individuals for BMI analyses and 1168 individuals for WC analyses who contributed to a total of 2767 and 1686 observations, respectively, over the 15-year follow-up period. For BMI analyses, the study population included 192 (16\%) participants with one observation, 542 (40\%) with two observations and the remaining 497 (44\%) participants had observations at all three time points. For WC, the study population included 650 (56\%) with one observation and the remaining 518 (44\%) participants had observations at two time points. Participants' age ranged from 25 to 75 years at baseline (age: men, $49 \cdot 8$ (SD 13.1); women, 48.4 (SD 12.0) years).

The study was approved by the Ethics Committee of the Queensland Institute of Medical Research (Brisbane, QLD, Australia) and all participants provided informed written consent.

\section{Anthropometric examinations}

Weight was measured in the clinic using calibrated electronic weighing scales. Calibration was performed each day using standardised weights. Participants, wearing light clothing without shoes or socks, were asked to stand straight and relaxed on the weighing scale until a stable reading was displayed. Weight was then recorded to the nearest $0 \cdot 1 \mathrm{~kg}$. Standing height was measured to the nearest $0 \cdot 1 \mathrm{~cm}$ using a stationary stadiometer. Participants were measured twice, with the average of the two measurements calculated and used for analyses. BMI was calculated as weight in $\mathrm{kg}$ divided by height in $\mathrm{m}^{2}\left(\mathrm{~kg} / \mathrm{m}^{2}\right)$. WC was measured midway between the lower rib margin and the iliac crest in the horizontal plane using a flexible non-stretch fibreglass tape and was read to the nearest $\mathrm{mm}$.

\section{Dietary intake}

Dietary intake was assessed using a self-administered semiquantitative FFQ in 1992, 1996 and 2007. The FFQ was originally developed for the US Nurses' Health Study ${ }^{(11,12)}$ and adapted for the Australian setting and validated in the Nambour Study population ${ }^{(13-15)}$. Estimates of energy and alcohol showed reasonable to good correlation when compared with weighed food records (Spearman correlation coefficient 0.45 and 0.71 , respectively) ${ }^{(15)}$. The FFQ used in
1992 and 1996 included 129 food items. Because newer food items have become available in recent years, the FFQ was revised for the 2007 data collection, resulting in an expanded FFQ containing 151 food items. Participants were asked to report their usual intake over the previous 6 months, of each item, with nine frequency response options ranging from 'never' to 'four or more times per d'. Frequencies were converted to daily equivalents for statistical analyses. The amounts of foods were in household or common measures such as one slice, one tablespoon $(15 \mathrm{ml})$ or one cup $(250 \mathrm{ml})$, representing one standard serve for each food. For seasonal fruits and vegetables, the participants were asked to indicate how often these foods were eaten in a season, and a seasonality adjustment for these foods was applied in the calculation of food intakes. Nutrient intakes were calculated using Australian food composition data ${ }^{(16,17)}$.

Participants who did not indicate consumption frequencies for $\geq 10 \%$ of the FFQ food items and those with reported energy intakes (EI) outside the recommended normal ranges $\left(2100-14700 \mathrm{~kJ} / \mathrm{d}\right.$ for women, $3360-16800 \mathrm{~kJ} / \mathrm{d}$ for men) ${ }^{(12)}$ were a priori excluded from the analyses. Specifically, a total of seventy-three participants with extremely high EI were excluded (1992: 24 (2.2\%); 1996: 24 (2.1\%); 2007: 25 (3.5\%), and one participant (2007) with EI lower than the pre-defined allowable range.

\section{Diet quality}

We measured diet quality using DGI developed by McNaughton et al. ${ }^{(6)}$. The DGI was developed to reflect Dietary Guidelines for Australian Adults ${ }^{(7)}$ and consisted of fifteen food items, including dietary indicators of vegetables and legumes, fruit, total cereals, meat and alternatives, total dairy, fluids, salt, saturated fat, alcoholic beverages, added sugars and 'extra foods'. The indicators used were based on the dietary guidelines, cut-points, and food groupings by the Australian Guide to Healthy Eating, which provides ageand sex-specific recommendations for the consumption of food items in five core food groups (vegetables, fruits, cereals, meat and alternatives, and dairy) and 'extra foods ${ }^{(8)}$. Extra foods are defined as foods that are not essential to provide nutrient requirements and contain too much fat, sugar and salt ${ }^{(8)}$. For the calculation of all DGI components, the original method by McNaughton et al. ${ }^{(6)}$ was exactly replicated with two exceptions. Two components, salt use and fluid intake, were excluded from the calculation of the DGI, and the intake of fruits and vegetables was based on FFQ data rather than the short dietary questions, since data on these items were lacking in the Nambour FFQ in almost all the examination years.

Each component of the DGI was scored from 0 to 10, where 10 indicated that a participant was meeting the recommendation or had an optimal intake. For example, two servings per $\mathrm{d}$ of fruit (recommended amount) scored 10 points, one serving per $\mathrm{d}$ scored 5 points and no fruit consumption scored 0 points. The total DGI score was the sum of thirteen items so that the diet score had a possible range of $0-130$, 
with a higher score reflecting increased compliance with the dietary guidelines.

\section{Covariates}

Details of sociodemographic and lifestyle characteristics were collected through self-completed questionnaires in 1992, 1996 and 2007. Participants were considered to have a medical condition if they answered 'yes' to the question: 'Have you ever been told by a doctor/nurse that you have: glaucoma, gallstones, high cholesterol, high triglycerides, diabetes/high blood sugar, high blood pressure/hypertension, angina, heart attack, stroke, cancer?'. Physical activity was categorised based on self-reported engagement in walking (if no, categorised as sedentary; if yes, categorised as low physical activity level) or moderate or vigorous exercise in the past 2 weeks. Smoking status was ascertained based on the timing and number of pack-years smoked, calculated from the frequency and duration of cigarettes smoked, for each period preceding the assessment year of anthropometric measures and categorised as lifelong non-smoker, ex-smoker and current smoker (1-7 pack-years, $>7$ pack-years).

Alcohol consumption $(\mathrm{g} / \mathrm{d})$ was calculated from the FFQ data, and categorised based on the national alcohol guidelines ${ }^{(18)}$ : none, moderate $(\leq 40 \mathrm{~g} / \mathrm{d}$ men, $\leq 20 \mathrm{~g} / \mathrm{d}$ women $)$ and heavy $(>40 \mathrm{~g} / \mathrm{d}$ men, $>20 \mathrm{~g} / \mathrm{d}$ women). We also considered frequency of alcohol consumption based on the number of alcoholic drinks per week. Estimated EI $(\mathrm{kJ} / \mathrm{d})$ was used as a continuous variable.

Age (continuous), education (grade 12 or less, technical/ college diploma, trade/apprenticeship, bachelor or higher, other) and occupation categorised as professionals (e.g. manager or teacher), para-professionals (e.g. technicians) and non-professionals (e.g. trade persons or clerks) ${ }^{(19)}$ were assessed using the data collected at baseline in 1992. For women, self-reported current use of hormone replacement therapy (yes/no) and parity (nulliparous, one child, 2/3/4/ 5-7 children) were considered in the analyses.

\section{Statistical analysis}

The longitudinal associations between the quartiles of DGI score and change in BMI or WC were assessed using linear regression applying generalised estimating equations (GEE) approach $^{(20)}$. BMI and WC were used as continuous outcome variables. Change in each of the anthropometric measures (BMI and WC) per year in quartiles of the DGI score was calculated by including an interaction term between the variable and time (year of observation as a continuous variable). A $P$ value for the overall association between explanatory variable and change in anthropometric measures was derived from the likelihood ratio test for the interaction of DGI score by time. A $P$ value for subgroup comparisons within quartiles of the DGI score was derived from a Waldtest based on parameter estimates and standard error from the GEE model.

To assess the longitudinal likelihood of change from normal weight to overweight in quartiles of the DGI score, logistic regression applying GEE approach was carried out in a subsample of the study population with at least two body measures. In these analyses, dichotomous outcomes indicating change from normal weight to overweight $v$. no change were considered. Overweight was defined as BMI $\geq 25\left(\mathrm{~kg} / \mathrm{m}^{2}\right)$, or $\mathrm{WC} \geq 94(\mathrm{~cm})$ in men and $\mathrm{WC} \geq 80(\mathrm{~cm})$ in women.

The analyses were stratified by sex because the pattern of associations was expected to be different for men and women. The covariates were included as time-dependent (changing over time) or time-independent (constant over time) variables. For all time-dependent variables (medical condition, physical activity, alcohol consumption, smoking status, EI, and hormone replacement therapy use in women), data from 1992, 1996 and 2007 were used for BMI analyses and data from 1992 and 2007 for WC analyses. Age, education, occupation, parity in 2004 and weight loss attempts in the past 10 years were considered as time-independent variables.

Multivariable regression models were adjusted for confounders which were found to be significantly related to the selected anthropometric measures. To recognise the confounders, the covariates of interest were examined in a subsample of participants with complete data on selected covariates to make sure that change in outcomes is due to the covariates and not due to missing data in outcomes of interest. Covariates were considered as confounders if there was a $\pm 10 \%$ change in the outcome variable after inclusion of the covariate in the multivariable model $(P<0 \cdot 1)$. Estimated EI did not change the outcome variable and was not significantly correlated with the DGI score and therefore omitted from the multivariable analysis. Age (centred on the mean) and its squared value were used for adjustment in the multivariable model. BMI and WC at baseline (1992) were included in the multivariable models where appropriate and were used as categorical variables according to WHO criteria for overweight and obesity $^{(21)}$. We did not include weight loss attempts as confounder in the multivariable model due to the limited number of observations in the final examination year (2007), although in a subsample this variable was a confounder for the association between the DGI score and change in WC in both sexes and change in BMI in men.

In sensitivity analyses, we further adjusted the multivariable models for misreporting of EI, using the computed ratio of total EI to predicted BMR (EI/BMR) as proposed by Goldberg et $a l .{ }^{(22)}$ and $\mathrm{Black}^{(23)}$. Underreporting was estimated by calculating the confidence limits for the agreement between EI:BMR ratio and individual physical activity level according to recommendations for evaluating 'habitual' intake in individuals ${ }^{(23)}$. The $95 \%$ CI were calculated as follows: exp $( \pm 2$ $(S / 100))$, where $S=\sqrt{\left(\mathrm{CV}_{\mathrm{wB}}^{2}+\mathrm{CV}_{\mathrm{tP}}^{2}\right)}, \mathrm{CV}_{\mathrm{wB}}$ is the $\mathrm{CV}$ of the within-person variation for predictions of BMR using the Schofield equation ${ }^{(24)}$ and $\mathrm{CV}_{\mathrm{tP}}$ is the coefficient of variation of the total variation in physical activity level. We considered $15 \%$ of between-subject variation for physical activity level and $8.5 \%$ of within-subject variation for estimated BMR which are suggested as an average substitute value by Black $^{(23)}$. Individuals were classified as low energy reporters (EI:BMR < the lower 95\% CI) and non-low energy reporters (EI:BMR $\geq$ the upper $95 \% \mathrm{CI}$ ). To address misreporting of 
EI, multivariable models were repeated after exclusion of low energy reporters or adjustment for EI:BMR ratio. However, given that the results did not materially change, we decided to present the results without this adjustment.

To test the representativeness of the study sample, the characteristics of the participants included in the analyses were compared with those excluded due to missing data on anthropometric measures or dietary intake using multiple logistic regressions applying the GEE approach. Values of $P<0.05$ were considered statistically significant. All analyses were carried out using SAS statistical package version 9.1 (SAS Institute, Cary, NC, USA).

\section{Results}

The final cohort for this study consisted of 1231 individuals for BMI analyses and 1168 individuals for WC analyses who contributed to a total of 2767 and 1686 observations, respectively, over the 15-year follow-up period. Study participants who were excluded from the analysis due to missing data on body size or diet ( $n$ 390) were more likely to be physically active than their counterparts included in the analysis $(P=0 \cdot 02)$ (results not shown).

Baseline characteristics of the study participants according to the DGI score are displayed in Tables 1 and 2. Men and women who achieved the highest dietary quality tended to be older, consumed less alcohol and were less likely to have a medical condition. Men in the highest quartile of the DGI score were more likely to be non-smokers and moderately physically active. Women in the highest DGI score quartile were more likely to have a higher BMI at baseline. Education, occupation, EI and WC were not statistically different across the DGI quartile in both sexes at baseline.

Table 1. Characteristics of men according to dietary guideline index (DGI) quartile (Q) at baseline, Nambour Study

(Mean values, standard deviations and percentages, $n$ 444)

\begin{tabular}{|c|c|c|c|c|c|c|}
\hline & $\begin{array}{c}\text { Overall } \\
22 \cdot 2-122 \cdot 9\end{array}$ & $\begin{array}{c}\text { Q1 } \\
22 \cdot 2-60 \cdot 8\end{array}$ & $\begin{array}{c}\text { Q2 } \\
61 \cdot 0-72 \cdot 2\end{array}$ & $\begin{array}{c}\text { Q3 } \\
72 \cdot 3-84 \cdot 3\end{array}$ & $\begin{array}{c}\text { Q4 } \\
84 \cdot 4-122 \cdot 9\end{array}$ & $P^{*}$ \\
\hline$n$ & 444 & 111 & 111 & 111 & 111 & \\
\hline Age at baseline (years) & & & & & & $<0.0001$ \\
\hline Mean & $51 \cdot 1$ & $47 \cdot 6$ & $49 \cdot 3$ & $53 \cdot 3$ & $54 \cdot 3$ & \\
\hline $\mathrm{SD}$ & 13.4 & $12 \cdot 4$ & $13 \cdot 2$ & $14 \cdot 0$ & $12 \cdot 8$ & \\
\hline Energy intake (kJ) & & & & & & 0.5 \\
\hline Mean & 9981 & 9788 & 10153 & 10202 & 9782 & \\
\hline SD & 2550 & 2592 & 2454 & 2582 & 2573 & \\
\hline BMI $\left(\mathrm{kg} / \mathrm{m}^{2}\right)$ & & & & & & $1 \cdot 0$ \\
\hline Mean & $26 \cdot 5$ & $26 \cdot 3$ & $26 \cdot 5$ & $26 \cdot 6$ & $26 \cdot 5$ & \\
\hline SD & 3.5 & 3.7 & 3.6 & $3 \cdot 3$ & 3.6 & \\
\hline Waist circumference $(\mathrm{cm})$ & & & & & & 0.7 \\
\hline Mean & $96 \cdot 2$ & 95.4 & $96 \cdot 4$ & 96.9 & 95.9 & \\
\hline SD & $10 \cdot 2$ & $11 \cdot 0$ & $9 \cdot 2$ & $9 \cdot 5$ & $11 \cdot 1$ & \\
\hline Education (\%) & & & & & & 0.3 \\
\hline Grade 12 or less & 40 & 48 & 37 & 43 & 33 & \\
\hline Technical/college diploma & 16 & 14 & 17 & 17 & 17 & \\
\hline Trade/apprenticeship & 35 & 33 & 39 & 28 & 38 & \\
\hline Bachelor or higher & 9 & 5 & 7 & 12 & 12 & \\
\hline Occupation (\%) & & & & & & 0.5 \\
\hline Professional & 27 & 21 & 25 & 32 & 28 & \\
\hline Para-professional & 6 & 5 & 9 & 5 & 5 & \\
\hline Non-professional & 67 & 74 & 66 & 63 & 67 & \\
\hline Medical condition (\%) & & & & & & $<0.0001$ \\
\hline Yes & 44 & 33 & 32 & 50 & 61 & \\
\hline Physical activity (\%) & & & & & & 0.04 \\
\hline Sedentary & 41 & 44 & 38 & 44 & 38 & \\
\hline Low & 26 & 26 & 33 & 22 & 24 & \\
\hline Moderate & 20 & 10 & 21 & 24 & 26 & \\
\hline High & 13 & 20 & 8 & 10 & 12 & \\
\hline Smoking status (\%) & & & & & & $<0.0001$ \\
\hline Current smokert & 17 & 31 & 21 & 10 & 7 & \\
\hline Alcohol consumption (g, daily) (\%) $\ddagger$ & & & & & & $<0.0001$ \\
\hline None & 16 & 14 & 12 & 19 & 19 & \\
\hline Moderate & 76 & 67 & 79 & 79 & 78 & \\
\hline Heavy & 8 & 19 & 9 & 2 & 3 & \\
\hline Frequency of alcoholic beverages (per week) (\%) & & & & & & 0.003 \\
\hline None & 16 & 15 & 12 & 19 & 19 & \\
\hline$\leq 1$ & 23 & 16 & 22 & 23 & 32 & \\
\hline $2-4$ & 15 & 9 & 16 & 22 & 14 & \\
\hline $5+$ & 46 & 60 & 50 & 36 & 35 & \\
\hline
\end{tabular}

* Continuous variables: linear trends were identified using regression analysis. Categorical variables: significant differences were assessed using the $\chi^{2}$ test.

$\dagger$ Current smokers with $\geq 1$ pack-year; ex-smokers and non-smokers not shown.

$\ddagger$ Moderate: $\leq 40 \mathrm{~g} / \mathrm{d}$ men, heavy: $>40 \mathrm{~g} / \mathrm{d}$ men. 
Table 2. Characteristics of women according to dietary guideline index (DGI) quartile (Q) at baseline, Nambour Study (Mean values, standard deviations and percentages, $n$ 594)

\begin{tabular}{|c|c|c|c|c|c|c|}
\hline & $\begin{array}{c}\text { Overall } \\
25 \cdot 2-118 \cdot 8\end{array}$ & $\begin{array}{c}\text { Q1 } \\
25 \cdot 2-69 \cdot 2\end{array}$ & $\begin{array}{c}\text { Q2 } \\
69.4-81.5\end{array}$ & $\begin{array}{c}\text { Q3 } \\
81 \cdot 6-92 \cdot 3\end{array}$ & $\begin{array}{c}\text { Q4 } \\
92 \cdot 3-118 \cdot 8\end{array}$ & $P^{*}$ \\
\hline$n$ & 594 & 148 & 149 & 149 & 148 & \\
\hline Age (years) & & & & & & 0.01 \\
\hline Mean & $49 \cdot 2$ & $48 \cdot 1$ & $47 \cdot 2$ & $50 \cdot 5$ & 51.5 & \\
\hline $\mathrm{SD}$ & $12 \cdot 2$ & $13 \cdot 3$ & $11 \cdot 3$ & $12 \cdot 2$ & $11 \cdot 3$ & \\
\hline Energy intake (kJ) & & & & & & 0.2 \\
\hline Mean & 8154 & 7917 & 8457 & 8229 & 8011 & \\
\hline SD & 2209 & 2135 & 2272 & 2245 & 2163 & \\
\hline $\mathrm{BMI}\left(\mathrm{kg} / \mathrm{m}^{2}\right)$ & & & & & & 0.002 \\
\hline Mean & $25 \cdot 8$ & $25 \cdot 1$ & $25 \cdot 3$ & $25 \cdot 8$ & $27 \cdot 0$ & \\
\hline SD & 4.6 & $4 \cdot 2$ & $4 \cdot 8$ & 4.7 & 4.5 & \\
\hline Waist circumference $(\mathrm{cm})$ & & & & & & 0.2 \\
\hline Mean & $82 \cdot 7$ & 81.5 & 81.9 & 83.5 & 83.8 & \\
\hline SD & $10 \cdot 8$ & $10 \cdot 1$ & 11.7 & $11 \cdot 2$ & $10 \cdot 0$ & \\
\hline Education (\%) & & & & & & 0.3 \\
\hline Grade 12 or less & 65 & 71 & 67 & 58 & 66 & \\
\hline Technical/college diploma & 27 & 23 & 23 & 32 & 28 & \\
\hline Trade/apprenticeship & 3 & 3 & 4 & 3 & 3 & \\
\hline Bachelor or higher & 5 & 3 & 6 & 7 & 3 & \\
\hline Occupation (\%) & & & & & & 0.2 \\
\hline Professional & 19 & 16 & 15 & 25 & 19 & \\
\hline Para-professional & 6 & 4 & 5 & 6 & 8 & \\
\hline Non-professional & 75 & 80 & 80 & 69 & 73 & \\
\hline Medical condition (\%) & & & & & & 0.001 \\
\hline Yes & 50 & 41 & 46 & 49 & 64 & \\
\hline Physical activity (\%) & & & & & & 0.3 \\
\hline Sedentary & 35 & 38 & 34 & 34 & 34 & \\
\hline Low & 37 & 31 & 40 & 36 & 43 & \\
\hline Moderate & 20 & 26 & 18 & 21 & 15 & \\
\hline High & 8 & 5 & 8 & 9 & 8 & \\
\hline Smoking status (\%) & & & & & & 0.2 \\
\hline Current smoker $\dagger$ & 9 & 15 & 8 & 7 & 7 & \\
\hline Alcohol consumption (g, daily) (\%)‡ & & & & & & $<0.0001$ \\
\hline None & 27 & 30 & 23 & 21 & 35 & \\
\hline Moderate & 68 & 58 & 74 & 77 & 64 & \\
\hline Heavy & 5 & 12 & 3 & 2 & 1 & \\
\hline Frequency of alcoholic beverages (per week) & & & & & & $<0.0001$ \\
\hline None & 27 & 30 & 23 & 21 & 35 & \\
\hline$\leq 1$ & 41 & 30 & 44 & 47 & 43 & \\
\hline $2-4$ & 11 & 6 & 12 & 12 & 12 & \\
\hline $5+$ & 21 & 34 & 21 & 20 & 10 & \\
\hline
\end{tabular}

${ }^{*}$ Continuous variables: linear trends were identified using regression analysis. Categorical variables: significant differences were assessed using the $\chi^{2}$ test. + Current smokers with $\geq 1$ pack-year; ex-smokers and non-smokers not shown. $\ddagger$ Moderate: $\leq 20 \mathrm{~g} / \mathrm{d}$, heavy: $>20 \mathrm{~g} / \mathrm{d}$ women.

At study entry (1992), $40 \%$ of the participants were overweight (BMI 25-30) and 16\% were obese (BMI $\geq 30$ ). In terms of WC, $28 \%$ were at an increased risk of metabolic complications (WC $\geq 94 \mathrm{~cm}$ in men, $\geq 80 \mathrm{~cm}$ in women) and another $28 \%$ were at a substantially increased risk (WC $\geq 102 \mathrm{~cm}$ in men, $\geq 88 \mathrm{~cm}$ in women). Men gained on average $0.09 \mathrm{~kg} / \mathrm{m}^{2}$ per year or $1.05 \mathrm{~kg} / \mathrm{m}^{2}$ in total BMI, while women gained $0.16 \mathrm{~kg} / \mathrm{m}^{2}$ per year or $2.4 \mathrm{~kg} / \mathrm{m}^{2}$ in total BMI during the follow-up. In the same time period, there was an increase of $0.12 \mathrm{~cm} /$ year or $1.8 \mathrm{~cm}$ in total WC among men, and an increase of $0.25 \mathrm{~cm} /$ year or $3.8 \mathrm{~cm}$ in total WC among women. Compliance with Australian dietary guidelines, measured by DGI, was generally poor at each of the three examination years, although diet quality slightly improved over the assessment period (1992-7). Specifically, out of a possible total DGI score of 130 , in men the mean DGI score increased from 71.9 (SD 16.9) in 1992 to 73.3 (SD 17.2) in
1996 and to $76 \cdot 2$ (SD 15.9) in 2007. In women, the corresponding figures were $80 \cdot 6$ (SD 16.4), $80 \cdot 8$ (SD 15.8) and $83 \cdot 8$ (SD 15.3) (both $P$-trend from GEE $<0.05$ ).

In the present study, 3\% were classified as low energy reporters $(\mathrm{EI} / \mathrm{BMR} \leq 0 \cdot 71)$ (data not shown). EI/BMR was inversely correlated with BMI $(r-0.24)$ and WC $(r-0.23)$ (both $P=0 \cdot 0001$ ), indicating higher prevalence of underreporting in heavier individuals.

The associations between the DGI score based on available data in each examination year and change in BMI and WC are shown in Tables 3 (men) and 4 (women). In men, the DGI score was inversely associated with change in BMI and WC in unadjusted models, indicating that men with a higher diet quality score gained less BMI and WC over time. The association between the DGI score and change in BMI or WC was attenuated in multivariable adjusted models, but sub-group differences were present. Compared to men in the reference 
Table 3. Longitudinal change in anthropometric measures by dietary guideline index (DGI) quartiles (Q) in men, Nambour Study, 1992-7 (Mean values and $95 \%$ confidence intervals, $n 1192$ observations across 532 individuals)

\begin{tabular}{|c|c|c|c|c|c|c|c|c|c|}
\hline & \multicolumn{2}{|r|}{ Q1 } & \multicolumn{2}{|r|}{ Q2 } & \multicolumn{2}{|r|}{ Q3 } & \multicolumn{2}{|r|}{ Q4 } & \multirow[b]{2}{*}{$P^{*}$} \\
\hline & Mean & $95 \% \mathrm{Cl}$ & Mean & $95 \% \mathrm{Cl}$ & Mean & $95 \% \mathrm{Cl}$ & Mean & $95 \% \mathrm{Cl}$ & \\
\hline \multicolumn{10}{|c|}{ BMI change $\left(\mathrm{kg} / \mathrm{m}^{2}\right.$ per year) $\dagger$} \\
\hline DGI & \multicolumn{2}{|c|}{$22 \cdot 2-62 \cdot 3$} & \multicolumn{2}{|c|}{$62 \cdot 4-74 \cdot 2$} & \multicolumn{2}{|c|}{$74 \cdot 3-86 \cdot 3$} & \multicolumn{2}{|c|}{$86 \cdot 4-122 \cdot 9$} & \\
\hline Univariate & 0.13 & $0.09,0.17$ & $0 \cdot 11$ & $0.07,0.16$ & 0.05 & $0.02,0.09$ & 0.07 & $0.04,0.10$ & 0.03 \\
\hline$P \ddagger$ & \multicolumn{2}{|r|}{ Ref. } & \multicolumn{2}{|r|}{0.7} & \multicolumn{2}{|r|}{0.01} & \multicolumn{2}{|r|}{0.03} & \\
\hline $\begin{array}{l}\text { Multivariable model§ } \\
P \ddagger\end{array}$ & 0.09 & $\underset{\text { Ref }}{0.04,0.15}$ & 0.08 & $0.9^{0.04,0.14}$ & 0.05 & $0.2^{0.00,0.10}$ & 0.04 & $\begin{array}{l}-0.01,0.08 \\
0.05\end{array}$ & $0 \cdot 1$ \\
\hline $\begin{array}{l}\text { Multivariable model\| } \\
P \ddagger\end{array}$ & 0.11 & $\begin{array}{l}0.06,0.16 \\
\text { Ref. }\end{array}$ & $0 \cdot 10$ & $0.7^{0.05,0.14}$ & 0.06 & $0.1^{0.01,0.11}$ & 0.05 & $\begin{array}{l}0.00,0.09 \\
0.01\end{array}$ & 0.05 \\
\hline \multicolumn{6}{|c|}{$W C$ change (cm per year) $†$ f } & & & & \\
\hline DGI & \multicolumn{2}{|c|}{$22 \cdot 2-62 \cdot 4$} & \multicolumn{2}{|c|}{$62 \cdot 5-74.6$} & \multicolumn{2}{|c|}{$74 \cdot 7-86 \cdot 3$} & \multicolumn{2}{|c|}{$86 \cdot 4-122 \cdot 9$} & \\
\hline $\begin{array}{l}\text { Univariate } \\
P \neq\end{array}$ & 0.26 & $\begin{array}{l}0.10,0.41 \\
\text { Ref. }\end{array}$ & $0 \cdot 10$ & $\begin{array}{l}-0.05,0.26 \\
0.2\end{array}$ & -0.07 & $\begin{array}{l}-0.20,0.06 \\
0.002\end{array}$ & $0 \cdot 10$ & $\begin{array}{l}-0.01,0.22 \\
0.1\end{array}$ & 0.03 \\
\hline $\begin{array}{l}\text { Multivariable model§ } \\
P \ddagger\end{array}$ & 0.25 & $\begin{array}{l}0.03,0.47 \\
\text { Ref. }\end{array}$ & 0.13 & $\begin{array}{l}-0.09,0.34 \\
0.3\end{array}$ & 0.07 & $\begin{array}{l}-0.20,0.21 \\
0.02\end{array}$ & 0.16 & $\begin{array}{l}-0.03,0.35 \\
0.3\end{array}$ & 0.2 \\
\hline $\begin{array}{l}\text { Multivariable model }{ }^{\star \star} \\
P \ddagger\end{array}$ & 0.26 & $\begin{array}{l}0.03,0.48 \\
\text { Ref. }\end{array}$ & $0 \cdot 15$ & $\begin{array}{l}-0.06,0.36 \\
0.3\end{array}$ & 0.04 & $\begin{array}{l}-0.15,0.24 \\
0.04\end{array}$ & 0.15 & $\begin{array}{l}-0.03,0.34 \\
0.3\end{array}$ & 0.2 \\
\hline
\end{tabular}

Ref., reference; WC, waist circumference.

* $P$ value from likelihood ratio test for interaction of covariate by time.

† Values derived from the interaction between covariates and time using generalised estimating equation; data collected in 1992,1996 and 2007 for BMI, and in 1992 and 2007 for WC.

‡ Comparison between categories: $P$ values from Wald test based on parameter estimate and standard error from generalised estimating equations model.

$\S$ Adjusted for baseline age, education, smoking status and frequency of alcohol consumption.

\| Adjusted for baseline age, education, smoking status, frequency of alcohol consumption and baseline BMI (categorical).

I In 1996, 469 observations were omitted since WC was not measured.

${ }^{\star \star}$ Adjusted for baseline age, education, smoking status, frequency of alcohol consumption, physical activity and baseline WC (categorical).

category, men in the highest quartile had the lowest gain in BMI $\left(0.05 v \cdot 0 \cdot 11 \mathrm{~kg} / \mathrm{m}^{2}\right.$ per year, $\left.P=0.01\right)$, and those in the third quartile had the smallest increase in WC during follow-up $(0.04 v \cdot 0.26 \mathrm{~cm} /$ year, $P=0.04)$. In women, the DGI score was not associated with change in any of the anthropometric measures.
In addition, we examined the likelihood of change from normal weight to overweight by quartile of the DGI score (Tables 5 and 6). Compared to the reference group, men categorised in higher quartiles had a lower risk of becoming overweight (BMI $\geq 25$ ) or being at increased risk of metabolic complications (WC $\geq 94 \mathrm{~cm}$ ) during the follow-up, but none

Table 4. Longitudinal change in anthropometric measures by dietary guideline index (DGl) quartiles (Q) in women, Nambour Study, 1992-7 (Mean values and $95 \%$ confidence intervals, $n 1575$ observations across 699 individuals)

\begin{tabular}{|c|c|c|c|c|c|c|c|c|c|}
\hline & \multicolumn{2}{|r|}{ Q1 } & \multicolumn{2}{|r|}{ Q2 } & \multicolumn{2}{|r|}{ Q3 } & \multicolumn{2}{|r|}{ Q4 } & \multirow[b]{2}{*}{$P^{*}$} \\
\hline & Mean & $95 \% \mathrm{Cl}$ & Mean & $95 \% \mathrm{Cl}$ & Mean & $95 \% \mathrm{Cl}$ & Mean & $95 \% \mathrm{Cl}$ & \\
\hline \multicolumn{10}{|c|}{ BMI change $\left(\mathrm{kg} / \mathrm{m}^{2}\right.$ per year) } \\
\hline DGI & \multicolumn{2}{|c|}{$21 \cdot 5-70 \cdot 7$} & \multicolumn{2}{|c|}{$70 \cdot 8-82 \cdot 5$} & \multicolumn{2}{|c|}{$82 \cdot 6-93 \cdot 1$} & \multicolumn{2}{|c|}{$93 \cdot 2-123 \cdot 1$} & \\
\hline Univariate A & 0.17 & $0.12,0.23$ & 0.14 & $0.09,0.19$ & 0.16 & $0.12,0.20$ & 0.15 & $0.11,0.19$ & 0.8 \\
\hline$P \ddagger$ & \multicolumn{2}{|r|}{ Ref. } & \multicolumn{2}{|r|}{0.4} & \multicolumn{2}{|r|}{0.7} & \multicolumn{2}{|r|}{0.5} & \\
\hline Multivariable model§ & \multicolumn{2}{|r|}{$\begin{array}{l}\text { Ref. } \\
0.07,0.24\end{array}$} & \multicolumn{2}{|r|}{$0.04,0.20$} & \multicolumn{2}{|r|}{$\begin{array}{l}0.7 \\
0.09,0.25\end{array}$} & 0.17 & $0.09,0.25$ & 0.2 \\
\hline$P \ddagger$ & \multicolumn{2}{|r|}{ Ref. } & \multicolumn{2}{|r|}{0.3} & \multicolumn{2}{|r|}{0.6} & \multicolumn{2}{|r|}{0.7} & \\
\hline Multivariable model\| & 0.15 & $0.06,0.23$ & 0.10 & $0.02,0.18$ & 0.16 & $0.08,0.23$ & 0.16 & $0.09,0.24$ & 0.1 \\
\hline$P \ddagger$ & \multirow{2}{*}{\multicolumn{2}{|c|}{ Ref. }} & \multirow{2}{*}{\multicolumn{2}{|c|}{0.2}} & \multirow{2}{*}{\multicolumn{2}{|c|}{0.8}} & \multicolumn{2}{|r|}{0.6} & \\
\hline \multicolumn{5}{|c|}{$W C$ change (cm per year) +9} & & & & & \\
\hline DGI & \multicolumn{2}{|c|}{$25 \cdot 2-70 \cdot 8$} & \multicolumn{2}{|c|}{$70.9-82.9$} & \multicolumn{2}{|c|}{$83 \cdot 0-93 \cdot 7$} & \multicolumn{2}{|c|}{$93 \cdot 8-118 \cdot 8$} & \\
\hline Univariate model & 0.36 & $0.20,0.52$ & 0.24 & $0.07,0.40$ & 0.23 & $0.09,0.37$ & 0.18 & $0.05,0.32$ & 0.4 \\
\hline$P \ddagger$ & \multicolumn{2}{|r|}{ Ref. } & \multicolumn{2}{|r|}{0.3} & \multicolumn{2}{|r|}{0.2} & \multicolumn{2}{|r|}{0.1} & \\
\hline Multivariable model§ & 0.37 & $0.13,0.60$ & 0.24 & $-0.01,0.49$ & 0.34 & $0.09,0.59$ & 0.31 & $0.07,0.54$ & 0.8 \\
\hline$P \ddagger$ & & Ref. & & 0.3 & & 0.8 & & 0.6 & \\
\hline Multivariable mode $^{\star * *}$ & 0.37 & $0.15,0.60$ & 0.27 & $0.04,0.51$ & 0.38 & $0.14,0.63$ & 0.38 & $0.15,0.62$ & 0.7 \\
\hline$P \ddagger$ & & Ref. & & 0.4 & & 0.9 & & 0.9 & \\
\hline
\end{tabular}

Ref., reference; WC, waist circumference.

* $P$ value from likelihood ratio test for interaction of covariate by time.

† Values derived from the interaction between covariates and time using generalised estimating equation; data collected in 1992,1996 and 2007 for BMI, and in 1992 and 2007 for WC.

‡ Comparison between categories: $P$ values from Wald test based on parameter estimate and standard error from generalised estimating equations model.

$\S$ Adjusted for baseline age, occupation, physical activity, smoking status, frequency of alcohol consumption, hormone replacement therapy (HRT) use and parity.

\| Adjusted for baseline age, occupation, physical activity, smoking status, frequency of alcohol consumption, HRT use, parity and baseline BMI (categorical).

I In 1996, 612 observations were omitted since WC was not measured.

${ }^{\star *}$ Adjusted for baseline age, occupation, physical activity, smoking status, frequency of alcohol consumption, HRT use, parity, education and baseline WC (categorical). 
Table 5. Risk of change from normal weight to overweight category based on anthropometric measures by quartile (Q) of the dietary guideline index (DGI) score in men, Nambour Study, 1992-7

(Odds ratios, $95 \%$ confidence intervals and percentages, $n 659$ observations across 442 individuals)

\begin{tabular}{|c|c|c|c|c|c|c|c|c|c|}
\hline & \multicolumn{2}{|r|}{ Q1 } & \multicolumn{2}{|c|}{ Q2 } & \multicolumn{2}{|c|}{ Q3 } & \multicolumn{2}{|c|}{ Q4 } & \multirow[b]{2}{*}{$P_{\text {trend }}$} \\
\hline & OR & $95 \% \mathrm{Cl}$ & OR & $95 \% \mathrm{Cl}$ & OR & $95 \% \mathrm{Cl}$ & OR & $95 \% \mathrm{Cl}$ & \\
\hline \multicolumn{10}{|c|}{ General overweight $(\mathrm{BMI} \geq 25)^{*}$} \\
\hline DGI & \multicolumn{2}{|c|}{$24 \cdot 4-62 \cdot 3$} & \multicolumn{2}{|c|}{$62 \cdot 4-74 \cdot 2$} & \multicolumn{2}{|c|}{$74 \cdot 3-86 \cdot 3$} & \multicolumn{2}{|c|}{$86 \cdot 4-115 \cdot 9$} & \\
\hline Cases $(n)$ & \multicolumn{2}{|r|}{12} & \multicolumn{2}{|r|}{5} & \multicolumn{2}{|c|}{8} & \multicolumn{2}{|c|}{8} & \\
\hline Proportions (\%) & \multicolumn{2}{|r|}{17} & \multicolumn{2}{|r|}{9} & \multicolumn{2}{|c|}{13} & \multicolumn{2}{|c|}{15} & \\
\hline Univariate & 1.0 & & 0.45 & $0.20,1.01$ & 0.65 & $0.31,1.39$ & 0.66 & $0.32,1.37$ & 0.5 \\
\hline Multivariable model† & 1.0 & & 0.48 & $0.20,1.15$ & 0.68 & $0.30,1.56$ & 0.76 & $0.33,1.72$ & 0.7 \\
\hline \multicolumn{10}{|c|}{ Abdominal adiposity $(\mathrm{WC} \geq 94 \mathrm{~cm})^{\star}$} \\
\hline DGI & \multicolumn{2}{|c|}{$31 \cdot 5-62 \cdot 2$} & \multicolumn{2}{|c|}{$62 \cdot 3-74 \cdot 4$} & \multicolumn{2}{|c|}{$74 \cdot 5-86 \cdot 3$} & \multicolumn{2}{|c|}{$86 \cdot 4-115 \cdot 9$} & \\
\hline Cases $(n) \ddagger$ & \multirow{2}{*}{\multicolumn{2}{|c|}{$\begin{array}{l}12 \\
29\end{array}$}} & \multirow{2}{*}{\multicolumn{2}{|c|}{$\begin{array}{c}9 \\
17\end{array}$}} & \multirow{2}{*}{\multicolumn{2}{|c|}{$\begin{array}{c}9 \\
16\end{array}$}} & \multirow{2}{*}{\multicolumn{2}{|c|}{$\begin{array}{l}11 \\
16\end{array}$}} & \\
\hline Proportions (\%) & & & & & & & & & \\
\hline Univariate & 1.0 & & 0.52 & $0.20,1.40$ & 0.47 & $0.18,1.25$ & 0.49 & $0.19,1.25$ & 0.2 \\
\hline Multivariable model§ & 1.0 & & 0.53 & $0.17,1.68$ & 0.57 & $0.18,1.84$ & 0.73 & $0.23,2.29$ & 0.7 \\
\hline
\end{tabular}

WC, waist circumference.

* Study participants with at least two measures.

† Adjusted for baseline age, education, smoking status and frequency of alcohol consumption.

$\ddagger$ In 1996, 441 observations were omitted since WC was not measured.

$\S$ Adjusted for baseline age, education, smoking status, frequency of alcohol consumption and physical activity.

of the OR reached statistical significance. We repeated this analysis, comparing the reference group to men with a higher diet quality score categorised as one group (quartiles 2-4 combined). Men with better diet quality were $37 \%$ less likely to change from normal weight to overweight (BMI $\geq 25$ ) and $40 \%$ less likely to change from no risk to increased risk of metabolic complications (WC $\geq 94 \mathrm{~cm}$ ) during the 15-year time period (data not shown). In women, there was no difference in likelihood to change from normal to overweight based on BMI or WC by ranking of the DGI score. Furthermore, in sensitivity analyses, we additionally adjusted for EI to account for residual confounding (data not shown). This adjustment did not change the results presented in Tables 3-6.

\section{Discussion}

To our knowledge, this is the first study to examine the association between diet quality and change in body mass and fat distribution over an extended period of time in a community-based sample of Australian men and women. On average, men and women gained $2.3 \mathrm{~kg} / \mathrm{m}^{2}$ BMI and $3.0 \mathrm{~cm}$ WC over the 15-year follow-up period, with women having a substantially larger gain in both BMI and WC than men. Diet quality, measured by DGI, was generally poor at three examination years. This is similar to findings from national studies showing relatively poor compliance with dietary guidelines in the Australian population ${ }^{(6,25)}$.

Dietary quality was shown to modify weight gain in men only. Specifically, men with a higher diet quality were less

Table 6. Risk of change from normal weight to overweight category based on anthropometric measures by quartile (Q) of the dietary guideline index (DGI) score in women, Nambour Study, 1992-7

(Odds ratios, $95 \%$ confidence intervals and percentages, $n 864$ observations across 577 individuals)

\begin{tabular}{|c|c|c|c|c|c|c|c|c|c|}
\hline & \multicolumn{2}{|c|}{ Q1 } & \multicolumn{2}{|c|}{ Q2 } & \multicolumn{2}{|c|}{ Q3 } & \multicolumn{2}{|c|}{ Q4 } & \multirow[b]{2}{*}{$P_{\text {trend }}$} \\
\hline & OR & $95 \% \mathrm{Cl}$ & OR & $95 \% \mathrm{Cl}$ & OR & $95 \% \mathrm{Cl}$ & OR & $95 \% \mathrm{Cl}$ & \\
\hline \multicolumn{10}{|c|}{ General overweight $(\mathrm{BMI} \geq 25)^{*}$} \\
\hline DGI & \multicolumn{2}{|c|}{$21 \cdot 5-70 \cdot 6$} & \multicolumn{2}{|c|}{$70 \cdot 7-82 \cdot 4$} & \multicolumn{2}{|c|}{$82 \cdot 5-93 \cdot 1$} & \multicolumn{2}{|c|}{$93 \cdot 2-121 \cdot 1$} & \\
\hline Cases $(n)$ & \multicolumn{2}{|c|}{27} & \multicolumn{2}{|c|}{31} & \multicolumn{2}{|c|}{33} & \multicolumn{2}{|c|}{30} & \\
\hline Proportions (\%) & \multicolumn{2}{|r|}{14} & \multicolumn{2}{|c|}{15} & \multicolumn{2}{|c|}{15} & \multicolumn{2}{|c|}{13} & \\
\hline Univariate & $1 \cdot 0$ & & 1.07 & $0.63,1.83$ & 1.08 & $0.64,1.83$ & 0.92 & $0.54,1.58$ & 0.8 \\
\hline Multivariable model† & $1 \cdot 0$ & & 1.38 & $0.75,2.56$ & 1.42 & $0.78,2.61$ & 1.06 & $0.55,2.06$ & 0.8 \\
\hline \multicolumn{10}{|c|}{ Abdominal adiposity $(\mathrm{WC} \geq 80 \mathrm{~cm})^{*}$} \\
\hline DGI & \multicolumn{2}{|c|}{$30 \cdot 7-70 \cdot 6$} & \multicolumn{2}{|c|}{$70 \cdot 7-82 \cdot 9$} & \multicolumn{2}{|c|}{$83 \cdot 0-93 \cdot 7$} & \multicolumn{2}{|c|}{$93 \cdot 8-118 \cdot 3$} & \\
\hline Cases $(n) \ddagger$ & \multirow{2}{*}{\multicolumn{2}{|c|}{$\begin{array}{l}10 \\
17\end{array}$}} & \multirow{2}{*}{\multicolumn{2}{|c|}{$\begin{array}{l}21 \\
27\end{array}$}} & \multirow{2}{*}{\multicolumn{2}{|c|}{$\begin{array}{l}17 \\
23\end{array}$}} & \multirow{2}{*}{\multicolumn{2}{|c|}{$\begin{array}{l}22 \\
24\end{array}$}} & \\
\hline Proportions (\%) & & & & & & & & & \\
\hline Univariate & \multicolumn{2}{|l|}{1.0} & 1.77 & $0.76,4.12$ & 1.43 & $0.60,3.42$ & 1.55 & $0.67,3.58$ & 0.5 \\
\hline Multivariable model§ & $1 \cdot 0$ & & 2.49 & $0.93,6.63$ & $2 \cdot 04$ & $0 \cdot 72,5 \cdot 75$ & 1.77 & $0.67,4.64$ & 0.5 \\
\hline
\end{tabular}

WC, waist circumference.

* Study participants with at least two measures.

$\dagger$ Adjusted for baseline age, occupation, physical activity, smoking status, frequency of alcohol consumption, hormone replacement therapy (HRT) use and parity.

$\ddagger$ In 1996, 564 observations were omitted since WC was not measured.

$\S$ Adjusted for baseline age, occupation, physical activity, smoking status, frequency of alcohol consumption, HRT use, parity and education. 
likely to gain BMI and WC over time and change from normal to overweight during follow-up. In women, diet quality was neither associated with change in BMI or WC nor associated with the likelihood of becoming overweight. As the DGI is an indicator for the overall quality of diet, we did not attempt to tease out the individual contributions of its components to change in anthropometric measures.

Comparison with other studies is not straightforward due to different approaches in the statistical analysis techniques and construction of diet quality indices, such as choice of components, assignment of foods to food groups, choice of cut-off values, adjustment for EI and decisions on the relative contribution of the individual components to the total score. Despite these differences in methodology, there are similarities between indices such as focus on moderating consumption of dietary fats while encouraging more complex carbohydrate in the diet.

Previous evidence from longitudinal studies on the association between diet quality indices and obesity indicators is limited and cross-sectional data do not provide consistent evidence of an association ${ }^{(26)}$. Other studies we compared our results with were not adjusted for many of the confounders we examined in our analyses, except for a few ${ }^{(27,28)}$.

In men, the inverse association between DGI quartiles and obesity outcomes was supported by findings from the Framingham Offspring Study in the USA which indicated that greater diet quality, measured by diet quality index, was associated with lower weight gain in men over a time period of 8 years ${ }^{(27)}$. Our findings in men also concurred with those from another prospective US study, showing an inverse association between diet quality measured by the healthy eating index and obesity outcomes ${ }^{(28)}$. This analysis, however, was not stratified by sex. Also, a cross-sectional analysis of the Health Professionals' Follow-up Study showed an inverse association between diet quality, assessed by healthy eating index, and $\mathrm{BMI}^{(29)}$.

In women, the lack of association between diet quality and change in anthropometric measures is in line with a recent national cross-sectional study, using the DGI score ${ }^{(30)}$, but it contrasts earlier cross-sectional $^{(31)}$ and longitudinal reports ${ }^{(27)}$ indicating inverse associations between diet quality and obesity measures. Other previous cross-sectional studies investigating diet quality ${ }^{(32,33)}$ or dietary patterns ${ }^{(26)}$ in relation to obesity have shown mixed results.

The lack of association in women may be related to energy underreporting in those with a higher $\mathrm{BMI}^{(34)}$. In sensitivity analyses, we adjusted for energy misreporting, but the results remained unchanged. However, residual confounding may occur, because the DGI reflects a range of dietary behaviours, not EI only ${ }^{(30)}$. It may also result from reverse causality, that is, overweight individuals adopting a healthier diet to manage their weight ${ }^{(35)}$. Dieting is an issue mostly observed in female participants ${ }^{(36,37)}$ and this was confirmed in the present study. Overall, $22 \%$ of women reported that they had frequently tried to lose weight in the previous 10 years, while only $10 \%$ of men reported to do so (data not shown).

There is also the possibility of the presence of other healthrelated behaviours and lifestyle variables not measured in this study which may be related to both changes in dietary intake and diet quality or obesity measures, and thus may have caused uncontrolled confounding.

Evidence from cross-sectional $^{(26)}$ and longitudinal ${ }^{(38-43)}$ studies on the association between empirically derived dietary patterns and obesity outcomes has also showed mixed results. In longitudinal studies, some findings suggest that a dietary pattern characterised by reduced-fat dairy products, cereals and fruit is inversely associated with change in BMI among women and with WC in both men and women ${ }^{(38-40)}$. Similarly, dietary patterns characterised by whole-grain cereals, fruits and vegetables have been reported to be predictive of less gain in BMI and weight ${ }^{(41,42)}$. In contrast, in a Danish study, no clear association was found between the food scores derived by pattern analysis and change in BMI or WC over a 5-year or 11-year follow-up ${ }^{(43)}$.

The strengths of this study include direct measurement of $\mathrm{BMI}$ and $\mathrm{WC}$ at three consecutive time points, thus eliminating systematic bias due to self-reported body size. Further, a number of potential confounders were accounted for and sensitivity analyses performed to estimate the impact of underreporting. This study is one of few to prospectively examine association between diet quality and change in BMI and WC in Australian adults considering a range of confounding variables over time. This study was embedded in a longitudinal study of skin cancer; therefore, anthropometric and dietary assessment was not a primary reason for participation in the study, which may have reduced some participation bias. The dietary quality index selected for this study has been previously validated in a national sample in Australia ${ }^{(6)}$ and was reported to be inversely associated with some health indicators related to type-2 diabetes in men and women ${ }^{(30)}$. Overall, the use of dietary quality indices has several advantages over data-driven measures of dietary patterns in assessing associations between diet and health outcomes ${ }^{(5)}$. They are based on the existing knowledge of optimal dietary intakes, provide summary measures of overall dietary quality and are easy for the public to understand and interpret ${ }^{(44)}$.

Possible limitations of our study warrant consideration. In longitudinal analyses, loss to follow-up is a matter of concern. However, a main advantage of the applied statistical model GEE is that all available data over the follow-up period could be used. Moreover, results from sensitivity analyses indicated that participants with missing data on WC or BMI in 2007 did not significantly differ in age- and sex-adjusted mean DGI score in 1992 from those with available anthropometric data in 2007 (data not shown). Therefore, we believe that missing data are not a major limitation in our study.

As a further measure to prevent participation bias, we have adjusted the multivariable models for factors which were different between subjects included in and excluded from the study ${ }^{(45)}$. Another limiting factor may be reliance on selfreported lifestyle characteristics, such as physical activity, which may be subject to recall bias ${ }^{(46)}$.

In conclusion, despite the increasing prevalence of obesity worldwide, little is known about the association between diet quality and change in obesity measures over extended periods of time. Our findings add longitudinal evidence 
to the knowledge that weight gain is a problem which is widespread in the adult population, affecting both men and women. In the present study, men with a higher DGI score were less likely to gain BMI and WC and to change from normal to overweight over time. Men with the lowest diet quality score gained more than two-fold in BMI and WC (non-significantly) as compared to their counterparts with highest ranking of the score. Our findings of no association between diet quality and change in obesity measures in women indicate that the current obesity epidemic does not discriminate in its effects across groups of adult women with different diet quality levels and this remains to be further elucidated.

\section{Acknowledgements}

We thank the Nambour Skin Cancer Study participants for their continued support. We also thank Maria Celia Hughes and Torukiri Ibiebele for their contributions to collection and preparation of the anthropometric and dietary data, and particularly Maria Celia Hughes for assistance in statistical analysis. This study was supported by National Health and Medical Research Council of Australia (data collection). S. A. was supported by a University of Queensland Graduate School Research Travel Grant, a Top-Up Scholarship from the Queensland Institute of Medical Research and a World Bank Scholarship. S. A. contributed to the statistical analysis and writing of the manuscript; J. C. v. d. P. conceived the analysis plan, technical assistance in statistical analysis and assistance in writing the manuscript; G. M. W. provided technical assistance in statistical analysis; G. C. M. contributed to technical assistance and assistance in writing the manuscript; and P. H. L. provided significant advice, technical assistance in interpretation and assistance in writing the manuscript. None of the authors had a conflict of interest.

\section{References}

1. Australian Institute of Health and Welfare (2004) Health, Wellbeing and Body Weight. Characteristics of Overweight and Obesity in Australia, 2001. Canberra: AIHW (no. 13).

2. Australian Bureau of Statistics (2009) National Health Survey: Summary of Results, 2007-2008 (Reissue). Canberra: ABS (no. 4364.0)

3. World Health Organization (2003) Diet, Nutrition and the Prevention of Chronic Diseases, Report of a Joint WHO/ FAO Expert Consultation. WHO Technical Report Series no. 916. Geneva: WHO.

4. Newby PK \& Tucker KL (2004) Empirically derived eating patterns using factor or cluster analysis: a review. Nutr Rev 62, 177-203.

5. Waijers PM, Feskens EJ \& Ocke MC (2007) A critical review of predefined diet quality scores. BrJ Nutr 97, 219-231.

6. McNaughton SA, Ball K, Crawford D, et al. (2008) An index of diet and eating patterns is a valid measure of diet quality in an Australian population. J Nutr 138, 86-93.

7. National Health and Medical Research Council (2003) Dietary Guidelines for Australian Adults. http://www. nhmrc.gov.au/publications/synopses/_files/n33.pdf
8. Kellett E, Smith AS \& Schmerlaib Y (1998) Australian Guide to Healthy Eating. Canberra: Commonwealth Department of Health and Family Services.

9. Green A, Williams G, Neale R, et al. (1999) Daily sunscreen application and betacarotene supplementation in prevention of basal-cell and squamous-cell carcinomas of the skin: a randomised controlled trial. Lancet 354, 723-729.

10. van der Pols JC, Heinen MM, Hughes MC, et al. (2009) Serum antioxidants and skin cancer risk: an 8-year community-based follow-up study. Cancer Epidemiol Biomarkers Prev 18, 1167-1173.

11. Willett WC, Sampson L, Stampfer MJ, et al. (1985) Reproducibility and validity of a semiquantitative food frequency questionnaire. Am J Epidemiol 122, 51-65.

12. Willett W (1998) Nutritional Epidemiology, 2nd ed. New York, NY: Oxford University Press.

13. McNaughton SA, Marks GC, Gaffney P, et al. (2005) Validation of a food-frequency questionnaire assessment of carotenoid and vitamin $\mathrm{E}$ intake using weighed food records and plasma biomarkers: the method of triads model. Eur $J$ Clin Nutr 59, 211-218.

14. Marks GC, Hughes MC \& van der Pols JC (2006) Relative validity of food intake estimates using a food frequency questionnaire is associated with sex, age, and other personal characteristics. J Nutr 136, 459-465.

15. Marks GC, Hughes MC \& van der Pols JC (2006) The effect of personal characteristics on the validity of nutrient intake estimates using a food-frequency questionnaire. Public Health Nutr 9, 394-402.

16. Food Standards Australia New Zealand (1995) Nuttab95: Nutrient Data Table for Use in Australia. Canberra: Food Standards Australia New Zealand (FSANZ).

17. Food Standards Australia New Zealand (2006) Nuttab2006: Nutrient data table for use in Australia. Canberra: Food Standards Australia New Zealand (FSANZ).

18. National Health and Medical Research Council (2001) Australian Alcohol Guidelines. Health, Risks and Benefits. Canberra: NHMRC, Commonwealth of Australia (no. 1864961546).

19. Australian Bureau of Statistics (1997) Australian Standard Classification of Occupations (ASCO), 2nd ed. Canberra: ABS (no. 1220.0).

20. Zeger SL, Liang KY \& Albert PS (1988) Models for longitudinal data: a generalized estimating equation approach. Biometrics 44, 1049-1060.

21. World Health Organization (2000) Obesity: Preventing and Managing the Global Epidemic of obesity, Report of a WHO Consultation. WHO Technical Report Series no. 894. Geneva: WHO.

22. Goldberg GR, Black AE, Jebb SA, et al. (1991) Critical evaluation of energy intake data using fundamental principles of energy physiology: 1 . Derivation of cut-off limits to identify under-recording. Eur J Clin Nutr 45, 569-581.

23. Black AE (2000) Critical evaluation of energy intake using the Goldberg cut-off for energy intake:basal metabolic rate. A practical guide to its calculation, use and limitations. Int J Obes Relat Metab Disord 24, 1119-1130.

24. FAO/WHO/UNU (1985) Energy and Protein Requirements Report of a Joint FAO/WHO/UNU Expert Consultation. Geneva: World Health Organization.

25. Ball K, Mishra GD, Thane CW, et al. (2004) How well do Australian women comply with dietary guidelines? Public Health Nutr 7, 443-452.

26. Togo P, Osler M, Sorensen TI, et al. (2001) Food intake patterns and body mass index in observational studies. Int J Obes Relat Metab Disord 25, 1741-1751. 
27. Quatromoni PA, Pencina M, Cobain MR, et al. (2006) Dietary quality predicts adult weight gain: findings from the Framingham Offspring Study. Obesity (Silver Spring) 14, $1383-1391$.

28. Gao SK, Beresford SA, Frank LL, et al. (2008) Modifications to the Healthy Eating Index and its ability to predict obesity: the Multi-Ethnic Study of Atherosclerosis. Am J Clin Nutr $\mathbf{8 8}$, 64-69.

29. McCullough ML, Feskanich D, Rimm EB, et al. (2000) Adherence to the Dietary Guidelines for Americans and risk of major chronic disease in men. Am J Clin Nutr $\mathbf{7 2}$, 1223-1231.

30. McNaughton SA, Dunstan DW, Ball K, et al. (2009) Dietary quality is associated with diabetes and cardio-metabolic risk factors. J Nutr 139, 734-742.

31. McCullough ML, Feskanich D, Stampfer MJ, et al. (2000) Adherence to the Dietary Guidelines for Americans and risk of major chronic disease in women. Am J Clin Nutr 72, 1214-1222.

32. Toft U, Kristoffersen LH, Lau C, et al. (2007) The Dietary Quality Score: validation and association with cardiovascular risk factors: the Inter99 study. Eur J Clin Nutr 61, 270-278.

33. Rafferty AP, Anderson JV, McGee HB, et al. (2002) A healthy diet indicator: quantifying compliance with the dietary guidelines using the BRFSS. Prev Med 35, 9-15.

34. Livingstone MB \& Black AE (2003) Markers of the validity of reported energy intake. J Nutr 133, Suppl. 3, 895S-920S.

35. Rennie KL, Johnson L \& Jebb SA (2005) Behavioural determinants of obesity. Best Pract Res Clin Endocrinol Metab 19, 343-358.

36. Saarni SE, Silventoinen K, Rissanen A, et al. (2007) Recurrent dieting and smoking among Finnish men and women. Obesity (Silver Spring) 15, 1851-1859.
37. Timperio A, Cameron-Smith D, Burns C, et al. (2000) The public's response to the obesity epidemic in Australia: weight concerns and weight control practices of men and women. Public Health Nutr 3, 417-424.

38. Newby PK, Muller D, Hallfrisch J, et al. (2004) Food patterns measured by factor analysis and anthropometric changes in adults. Am J Clin Nutr 80, 504-513.

39. Newby PK, Muller D, Hallfrisch J, et al. (2003) Dietary patterns and changes in body mass index and waist circumference in adults. Am J Clin Nutr 77, 1417-1425.

40. McNaughton SA, Mishra GD, Stephen AM, et al. (2007) Dietary patterns throughout adult life are associated with body mass index, waist circumference, blood pressure, and red cell folate. J Nutr 137, 99-105.

41. Hu FB, Rimm EB, Stampfer MJ, et al. (2000) Prospective study of major dietary patterns and risk of coronary heart disease in men. Am J Clin Nutr 72, 912-921.

42. Schulz M, Nothlings U, Hoffmann K, et al. (2005) Identification of a food pattern characterized by high-fiber and low-fat food choices associated with low prospective weight change in the EPIC-Potsdam cohort. J Nutr 135, 1183-1189.

43. Togo P, Osler M, Sorensen TIA, et al. (2004) A longitudinal study of food intake patterns and obesity in adult Danish men and women. Int J Obes Relat Metab Disord 28, 583-593.

44. Michels KB \& Schulze MB (2005) Can dietary patterns help us detect diet-disease associations? Nutr Res Rev $\mathbf{1 8}$ $241-248$.

45. Savitz DA (2003) Interpreting Epidemiologic Evidence: Strategies for Study Design and Analysis. New York, NY: Oxford University Press.

46. Wareham N (2007) Physical activity and obesity prevention. Obes Rev 8, 109-114. 